\title{
Statt eines Nachworts
}

Folgende zehn „Fragegebote“ sollen Ihnen dabei helfen, besser systemisch zu fragen:

1. Bevor Sie eine Frage stellen: Reflektieren Sie Ihre Hypothese, warum und mit welchem Hintergrund Sie diese Frage stellen.

2. Formulieren Sie die Frage kurz und prägnant, am besten mit Sieben-WortSätzen.

3. Formulieren Sie nur eine Frage je Satz.

4. Machen Sie Pausen beim Fragen - lassen Sie (sich) Zeit zum Nachdenken.

5. Eliminieren Sie suggestive und inquisitorische Fragen aus Ihrem Repertoire.

6. Bringen Sie gezielt Abwechslung in die Frageworte. Variieren Sie: was... welche... woran... wie... inwieweit... wodurch... wann... inwiefern... woher...

7. Achten Sie auf Ihre Stimme und Körpersprache.

8. Formulieren Sie hypothetische und zirkuläre Fragen.

9. Führen Sie durch skalierende Fragen Unterschiede ein.

10. Fragen Sie anknüpfend - d. h., nehmen Sie Bezug auf vorangegangene Aussagen. 